\title{
The Significance of Right Ventricular Ischemia in Reflex Bradycardia in Humans
}

\author{
Isao Kubota, M.D., * Sukehiko Kawashima, M.D., \\ Tomoyasu Yahagi, M.D., Toshikazu Goto, M.D., \\ Tamio MiURA, M.D., Takao ARAKI, M.D., \\ and Koichi YOKOYama, M.D.
}

\begin{abstract}
SuMmary
Heart rates (HR) were measured before (control HR) and after (ischemic $H R$ ) balloon inflation during percutaneous transluminal coronary angioplasty in 96 patients with effort angina pectoris. The delta HR, defined as (ischemic $\mathrm{HR}$-control $\mathrm{HR}$ ), in the right coronary artery occlusion was significantly smaller than that in the left anterior descending artery or left circumflex artery occlusion. Among right coronary artery occlusions the delta $\mathrm{HR}$ in segment 1 occlusion was significantly smaller than that in segment 2 or segment 3 occlusion. It is suggested that the ischemia of the right ventricle plays an important role in producing a reflex bradycardic response in humans. (Jpn Heart J 35: 727-732, 1994)
\end{abstract}

Key words: Percutaneous transluminal coronary angioplasty BezoldJarisch reflex Bradycardia Effort angina pectoris

T $\mathrm{N}$ patients with variant angina pectoris ${ }^{1,2)}$ or acute myocardial infarction, ${ }^{3-5)}$ the heart rate decreases in most patients who show ST-segment elevation in inferior leads and increases in most cases who show ST-segment elevation in anterior leads. The former phenomenon is considered to be attributed to the enhanced vagal activity induced by the myocardial ischemia in the inferoposterior wall of the left ventricle (Bezold-Jarisch reflex $\left.{ }^{6}\right)$. However, the heart rate response during various sites of acute myocardial ischemia has not been fully investigated in humans. The purpose of this study was to examine the relationship between the site of acute myocardial ischemia and the heart rate change using patients with effort angina pectoris without myocardial infarction who underwent percutaneous transluminal coronary angioplasty (PTCA). Particularly, we examined the role of right ventricular ischemia in producing a reflex

\footnotetext{
From *The First Department of Internal Medicine, Yamagata University School of Medicine, and Department of Internal Medicne, Yamagata Prefectural Central Hospital, Yamagata 990, Japan.

Address for correspondence: Isao Kubota, M.D., The First Department of Internal Medicine, Yamagata University School of Medicine, Yamagata 990-23, Japan.

Received for publication September 26, 1994.

Accepted November 7, 1994.
} 
bradycardic response.

\section{Methods}

Patients: Between January 1986 and September 1992, a total of 1166 patients underwent PTCA in Yamagata Prefectural Central Hospital. Of these patients, 96 cases with effort angina pectoris without myocardial infarction $(72 \mathrm{men}$ and 24 women, mean 62.2 years old) who satisfied all of the following criteria were selected for this study. 1) First experience of PTCA and at least one of the balloon inflation times $\geq 60$ seconds, 2) Appearance of ST-segment elevation ( $\geq 0.1 \mathrm{mV}$ ) on the corresponding leads during PTCA, 3) No occluded coronary artery and the presence of significant $(\geq 75 \%)$ stenosis on coronary arteriogram, 4) No akinetic left ventricular wall motion on left ventriculogram and/or echocardiogam, and 5) No history of myocardial infarction, and no electrocardiographic evidence of pathologic $Q$ waves, intraventricular conduction disturbances, ST- segment changes or inverted T waves. Patients who showed frequent premature beats or received an intravenous infusion of atropine during PTCA were excluded.

Of the 96 patients, 76 had single vessel disease, 13 had double and 8 had triple vessel disease. The number of balloon inflated vessels was 109; right coronary artery (RCA) 3l, left anterior descending artery (LAD) 67 and left circumflex artery (LCx) Il. At the time of PTCA, Ca channel blockers, long acting nitrates and beta-blockers were administered in 83, 81 and 5 patients, respectively. Five patients received none of these drugs.

Heart rate response measurement: Heart rates (HRs) were calculated by averaging the RR interval of the consecutive 8 beats just before the balloon inflation (control HR) and just before the time when sixty seconds passed (ischemic HR). Delta HR was defined as ischemic HR minus control HR. The site of the balloon inflation (occlusion) was determined according to the reporting system of the American Heart Association. ${ }^{7)}$ The differences between the control HR and ischemic HR were assessed in the RCA, LAD and LCx occluded groups. Mean control HR, ischemic HR and delta HR were compared among the RCA, LAD and LCx occlusion groups. The differences in mean delta HR among the occlusions of segments 1, 2 and 3 of the RCA were also investigated. Statistical analysis: Analysis of variance with Scheffe's test was used for comparison of mean control HR, mean ischemic HR and mean delta HR between the groups and the paired $t$ test was used for analysis of the HR changes within each group. A $p$ value $<0.05$ was considered to be statistically significant. Quantitative data are expressed as mean $\pm \mathrm{SD}$. 


\section{Results}

The table shows the mean control HR and mean ischemic HR in the RCA, LAD and LCx occluded groups. The ischemic HR of the RCA occluded group was significantly lower than that of the LAD occluded group $(p<0.001)$ or $\mathrm{LCx}$ occluded group $(p<0.01)$, while there were no significant differences in the control HR among the three groups. In the RCA occluded group the ischemic HR was significantly lower than the control $\mathrm{HR}(p<0.001)$ and in the LAD occluded group the ischemic HR was significantly higher than the control $\mathrm{HR}$ $(p<0.001)$. There was no significant difference between the ischemic HR and the control HR in the LCx occluded group.

Figure 1 illustrates the differences in delta HR among the three groups. The

Table. Mean control and ischemic heart rate in RCA, LAD and LCx occluded groups

\begin{tabular}{llll}
\hline & Control HR & Ischemic HR & Significance \\
\hline RCA & $69.5 \pm 10.4$ & $63.8 \pm 8.6^{\mathrm{A}, \mathbf{B}}$ & $p<0.00 \mathrm{I}$ \\
LAD & $73.5 \pm 13.3$ & $77.7 \pm 15.3^{\mathrm{A}}$ & $p<0.001$ \\
LCx & $75.8 \pm 11.9$ & $78.7 \pm 13.1^{\mathrm{B}}$ & NS \\
\hline
\end{tabular}

Data are expressed as mean $\pm \mathrm{SD}$. ${ }^{\mathrm{A}}, p<0.001{ }^{\mathrm{B}}, p<0.01$ between the two ischemic $\mathrm{HRs}$. $\mathrm{RCA}=$ right coronary artery; $\mathrm{LAD}=$ left anterior descending artery; $\mathrm{LCx}=$ left circumflex artery; $\mathrm{HR}=$ heart rate.

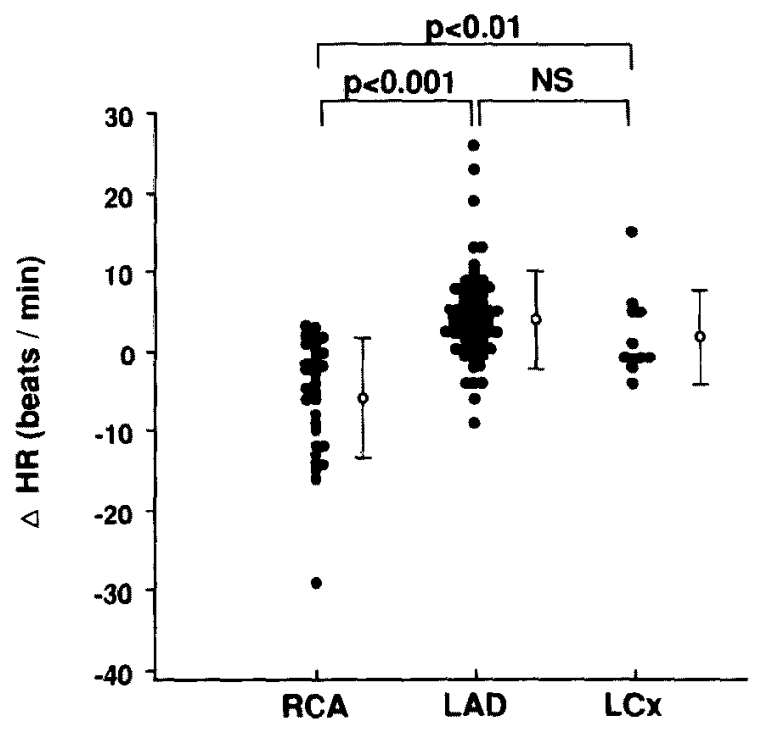

Figure 1. Differences in delta $H R(\triangle H R$ ) among the right coronary artery (RCA), left anterior descending artery $(\mathrm{LAD})$ and left circumflex artery $(\mathrm{LCx})$ occluded groups. The delta HR of the RCA occluded group was significantly lower than that of the LAD or LCx occluded group. 


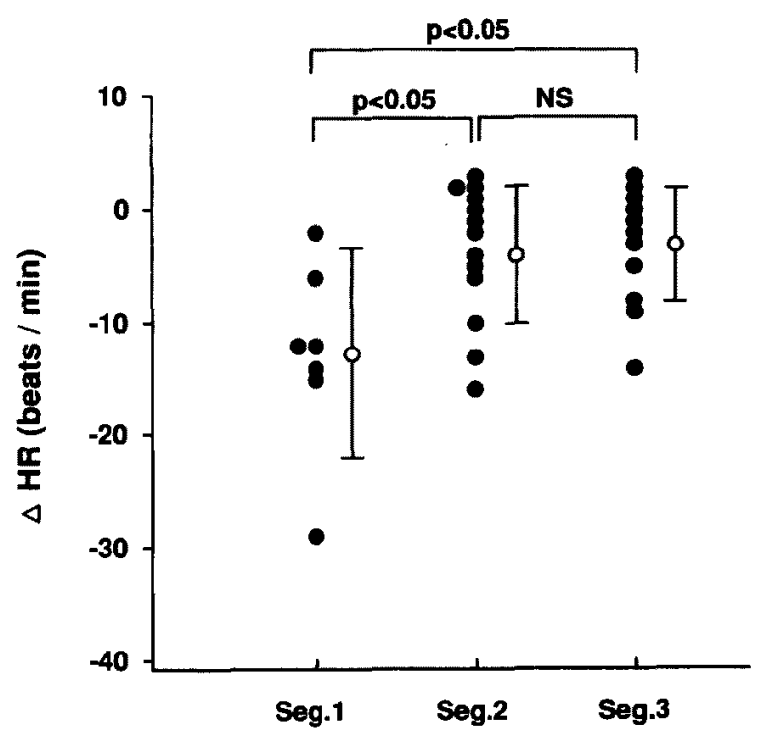

Figure 2. Differences in delta $H R(\Delta H R)$ among the segment 1 (Seg. 1), 2 (Seg. 2) and 3 (Seg. 3) occluded subgroups. The delta HR of the segment 1 occlusion group was significantly lower than that of the segment 2 or segment 3 occlusion group.

delta HR of the RCA occluded group $(-5.7 \pm 7.4)$ was significantly lower than that of the $\operatorname{LAD}(4.2 \pm 5.9 ; p<0.001)$ or $\operatorname{LCx}(2.0 \pm 5.4 ; p<0.01)$ occluded group. There was no significant difference in delta HR between the LAD and the LCx occluded groups. Figure 2 presents the differences in delta HR among the segment 1, 2 and 3 occlusions in the RCA occluded group. There were no cases of balloon inflation in segment 4 in the present population. The delta HR of the segment 1 occlusion $(-12.9 \pm 8.5)$ was significantly lower than that of the segment $2(-3.8 \pm 6.1 ; p<0.05)$ or segment $3(-3.3 \pm 5.3 ; p<0.05)$ occlusion.

\section{Discussion}

Although the acute ischemia in the inferoposterior wall of the left ventricle has been reported to stimulate vagal activity and induce sinus bradycardia in dogs,${ }^{8}$ there have been few studies that directly evaluate both the heart rate and the site of myocardial ischemia in humans. Araki et $\left.\mathrm{a}^{2}{ }^{2}\right)$ reported that in patients with variant angina inferior ischemia was accompanied by a decrease but anterior ischemia by an increase in heart rate by means of a Holter ECG recording system, and concluded that these changes were elicited by activation of cardiac receptors. The present study was done to further investigate the heart rate response during different sites of acute myocardial ischemia in patients with effort angina pectoris who underwent PTCA, since the ischemic region can be local- 
ized precisely in this study design. Because myocardial infarction is considered to alter autonomic nerve activity, ${ }^{9,10)}$ patients who had not only documented myocardial infarction but also left ventricular akinesis or occluded coronary artery were excluded. The presence of acute myocardial ischemia during PTCA was confirmed by the appearance of ST-segment elevation in all patients.

Heart rate changes in the LAD occluded group and in the RCA occluded group were compatible with the findings reported in patients with variant angina. ${ }^{2)}$ However, the significant decrease in heart rate was observed only in the RCA occluded group but not in the LCx occluded group (Table). In fact, a delta HR equal to or less than -5 was observed in 15 of the 32 occlusions $(48 \%)$ of RCA, but in none of the 11 occlusions $(0 \%)$ of LCx. Out of the 11 balloon inflations to LCx, 3 were conducted in patients with a prominent left circumflex artery. Even when most of the inferoposterior wall of the left ventricle was supplied by the LCx, the heart rate did not show an obvious decrease (delta HR $=5$, -1 and -1 ). These results do not accord with the common notion that the bradycardic response during myocardial ischemia was caused by activation of inhibitory cardiac receptors with vagal afferents distributed predominantly in the inferoposterior wall of the left ventricle. Further study using a larger number of cases with a predominant left circumflex artery is required to test the validity of this notion.

Among the RCA occlusions, the delta HR of the segment 1 occlusion was significantly lower than that of the segment 2 or 3 occlusion. Because all of the balloon inflation sites to segment 1 were located distal to the divergence of the sinus node artery, the effect of the sinus node ischemia on the heart rate changes was judged to be neglected in the present study. If only the ischemia of the inferoposterior wall of the left ventricle provokes the reflex bradycardia, the delta HR among the three groups should be similar because all of the occluded sites were proximal to the branches to the left ventricle. However, this was not the case. The result cannot be explained unless the ischemia of the right ventricle is involved in the development of the bradycardic response. However, we could not obtain evidence indicating that the ischemia limited to the right ventricle produces the bradycardic response in this study since we usually do not perform PTCA to the poorly developed right coronary artery and we selected patients with ST-segment elevation in II, III, and aVF when the right coronary artery was occluded.

There were several cases who showed delta HR $\leq-5$ both in LAD occlusion and in RCA segment 2 or 3 occlusion. In these cases, the response is considered to be related to the ischemia of the inferoposterior wall of the left ventricle rather than that of the right ventricle.

In conclusion, the findings of this study have demonstrated that the 
bradycardic response in humans is augmented when the ischemia extends from the inferoposterior wall of the left ventricle to the right ventricle, suggesting that vagal afferents responsible for the reflex bradycardia are located not only in the inferoposterior wall of the left ventricle, but also in the right ventricle.

\section{REFERENGES}

1. Perez-Gomez F, Martin de Dios R, Rey J, Garcia Aguado A: Prinzmetal's angina; reflex cardiovascular response during episode of pain. $\mathrm{Br}$ Heart $\mathrm{J}$ 42: 81, 1979

2. Araki $H$, Anan $T$, Koiwaya $Y$, Nakagaki $O$, Takeshita $A$, Nakamura $M$ : Reflex heart rate and blood pressure changes during ST segment elevation in patients with variant angina. Am Heart J 108: 1273, 1984

3. Webb SW, Adgey AA, Pantridge JF: Autonomic disturbance at onset of acute myocardial infarction. Br Med J 3: 89, 1972

4. Adgey AA, Geddes JS, Mulholland HC, Keegan DA, Pantridge JF: Incidence, significance, and management of early bradyarrhythmia complicating acute myocardial infarction. Lancet 2: 1097, 1968

5. Scheinman MM, 'Thorburn D, Abboud JA: Use of atropine in patients with acute myocardial infarction and sinus bradycardia. Circulation 52: 627, 1975

6. Abboud FM, Eckberg DC, Kioschos JM, White CM: The Bezold-Jarisch reflex in man. In Cardiac Receptors, ed by Hainsworth R, Kidd C, Linden RJ, Cambridge University Press, Cambridge, p463, 1979

7. A reporting system on patients evaluated for coronary artery discase; report of the Ad Hoc committee for grading of coronary artery disease. Council on Cardiovascular Surgery American Heart Association. News from the American Heart Association. Circulation 51: 31, 1975

8. Thames MD, Klopfenstein HS, Abboud FM, Mark AL, Walker JL: Preferential distribution of inhibitory cardiac receptors with vagal afferents to the inferoposterior wall of the left ventricle activated during coronary occlusion in the dog. Circ Res 43: 512,1978

9. Barber MJ, Mueller TM, Henry DP, Felten SY, Zipes DP: Transmural myocardial infarction in the dog produces sympathectomy in noninfarcted myocardium. Circulation 67: 787, 1983

10. Barber MJ Mueller TN, Davies BG, Gill RM, Zipes DP: Interruption of sympathetic and vagalmediated afferent responses by transmural myocardial infarction. Circulation 72: 623, 1985 